\title{
IL-7 receptor blockade following T cell depletion promotes long-term allograft survival
}

\author{
Hoa-Le Mai, ${ }^{1}$ Françoise Boeffard,1 Julie Longis, ${ }^{1}$ Richard Danger, ${ }^{1}$ Bernard Martinet, ${ }^{1}$ \\ Fabienne Haspot, ${ }^{1}$ Bernard Vanhove, ${ }^{1,2}$ Sophie Brouard,1 and Jean-Paul Soulillou'1,2 \\ 1INSERM UMR 1064, Institut de Transplantation Urologie-Nephrologie (ITUN), Centre Hospitalier Universitaire (CHU) de Nantes, \\ University of Nantes, Nantes, France. ${ }^{2}$ Effimune, Nantes, France.
}

\begin{abstract}
T cell depletion is commonly used in organ transplantation for immunosuppression; however, a restoration of $\mathrm{T}$ cell homeostasis following depletion leads to increased memory $\mathrm{T}$ cells, which may promote transplant rejection. The cytokine IL-7 is important for controlling lymphopoiesis under both normal and lymphopenic conditions. Here, we investigated whether blocking IL-7 signaling with a mAb that targets IL-7 receptor $\alpha$ (IL-7R $\alpha$ ) alone or following T cell depletion confers an advantage for allograft survival in murine transplant models. We found that IL-7R blockade alone induced indefinite pancreatic islet allograft survival if antiIL-7R treatment was started 3 weeks before graft. IL-7R blockade following anti-CD4- and anti-CD8-mediated T cell depletion markedly prolonged skin allograft survival. Furthermore, IL-7 inhibition in combination with $T$ cell depletion synergized with either CTLA-4Ig administration or suboptimal doses of tacrolimus to induce long-term skin graft acceptance in this stringent transplant model. Together, these therapies inhibited $\mathrm{T}$ cell reconstitution, decreased memory $T$ cell numbers, increased the relative frequency of Tregs, and abrogated both cellular and humoral alloimmune responses. Our data suggest that IL-7R blockade following $T$ cell depletion has potential as a robust, immunosuppressive therapy in transplantation.
\end{abstract}

\section{Introduction}

T cell depletion by antibodies is one of the most potent immunosuppressive therapies and is increasingly used as an induction therapy in organ transplantation (1). However, T cell homeostasis after depletion therapy leads to a predominance of memory T cells (1-3), which are more potent than naive $T$ cells in mediating graft rejection and present as a major obstacle to achieving tolerance. Mice undergoing $\mathrm{T}$ cell homeostatic proliferation following depletion therapy rejected cardiac allograft despite costimulatory blockade by CTLA-4Ig, a treatment capable of inducing tolerance in nondepleted mice $(4,5)$. In human, kidney transplant patients who had received $\mathrm{T}$ cell depletion therapy by high-dose alemtuzumab, but no maintenance immunosuppression, uniformly developed acute rejection within the first month after transplantation (6), a period during which there was still a severe $\mathrm{T}$ cell lymphopenia but most of the remaining $\mathrm{T}$ cells were effector memory $\mathrm{T}$ cells (7).

$T$ cell reconstitution after depletion therapy comprises de novo thymopoiesis and homeostatic proliferation of remaining peripheral T cells, and both processes are IL-7 dependent $(8,9)$. IL-7 signals through the IL-7 receptor (IL-7R) which is composed of 2 chains, the common $\gamma$ chain and the $\alpha$ chain (IL-7R $\alpha$ or CD127) (10). IL-7 plays an essential, nonredundant role in lymphopoiesis, since IL-7 or IL-7R $\alpha$ knockout mice have severe T and B cell lymphopenia $(11,12)$ and infants with IL-7R $\alpha$ mutations have severe $\mathrm{T}$ cell lymphopenia necessitating bone marrow transplantation (13). IL-7 has also been shown to be necessary for the homeostatic

Authorship note: Sophie Brouard and Jean-Paul Soulillou are co-senior authors and are listed by alphabetical order.

Conflict of interest: Bernard Vanhove and Jean-Paul Soulillou receive consultant fees from Effimune.

Citation for this article: J Clin Invest. 2014;124(4):1723-1733. doi:10.1172/JCI66287. proliferation of both naive and memory $\mathrm{CD}^{+}$and $\mathrm{CD}^{+} \mathrm{T}$ cells in lymphopenic conditions (14-18). Therefore, in the setting of organ transplantation, the blockade of IL-7/IL-7R signaling is expected to prolong the effects of $\mathrm{T}$ cell depletion therapy, reduce the number of memory $\mathrm{T}$ cells, and increase immunoregulation, leading to better graft acceptance (19).

In this study, we investigated the role of IL-7R blockade by an anti-IL-7R $\alpha \mathrm{mAb}$, first given alone in an islet allograft model and then given after $T$ cell depletion by a combination of anti-CD4 and anti-CD $8 \mathrm{mAbs}$ in a more stringent skin allograft model. We also elucidated the mechanisms underlying the therapeutic efficacy of IL-7R blockade in transplantation.

\section{Results}

IL-7R blockade reduces almost all lymphocyte subset numbers and increases Treg frequency. The anti-IL-7R $\alpha \mathrm{mAb}$ (A7R34) used in our study was previously shown to block IL-7R and reduce lymphocyte numbers when given at $2 \mathrm{mg}$ every other day (qod) for 2 weeks (20). In this study, we tested a lower dose of A7R34 and were able to produce similar effects. Naive BALB/c mice were injected with either PBS or A7R34 $400 \mu \mathrm{g}$ qod for 3 weeks and sacrificed. AntiIL-7R $\alpha$-treated mice had significantly lower numbers of total lymphocytes, $\mathrm{T}$ cells, $\mathrm{CD} 4^{+} \mathrm{T}$ cells, $\mathrm{CD}^{+} \mathrm{T}$ cells, and $\mathrm{B}$ cells in the LNs, spleen, and peripheral blood and drastically reduced numbers of thymocytes in the thymus compared with control mice (Supplemental Figure 1, A-D; supplemental material available online with this article; doi:10.1172/JCI66287DS1). Interestingly, we found a significant increase in the percentage of $\mathrm{CD}^{+} \mathrm{T}$ cells expressing programmed death 1 (PD-1) and an increase in the percentage of $\mathrm{CD}^{+} \mathrm{CD}_{25}{ }^{+} \mathrm{FOXP3} 3^{+}$Tregs in the LNs and spleens of treated mice compared with those of control mice (Supplemental Figure 1, $A$ and $B)$, in concordance with recent publications $(21,22)$. On 

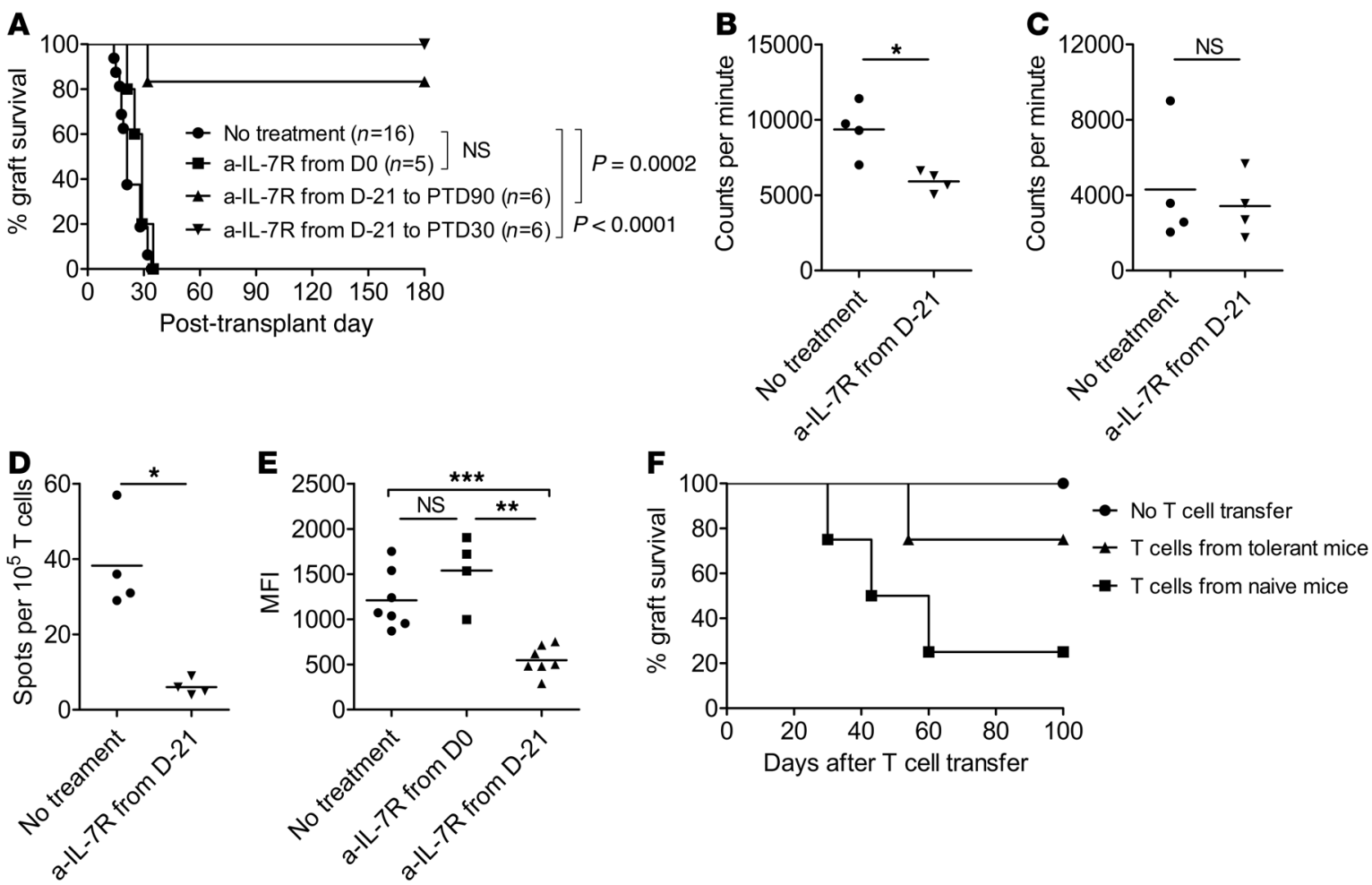

\section{Figure 1}

IL-7R blockade started 3 weeks before graft induces islet allograft tolerance and abrogates both cellular and humoral alloimmune responses. (A-E) BALB/c mice previously rendered diabetic by STZ received C57BL/6 islet graft and were treated as indicated. (A) Anti-IL-7R $\alpha \mathrm{mAb}$ given from D-21 to either PTD90 or PTD30 induced indefinite graft survival in most or all of mice. (B and C) MLR with 3 H-thymidine incorporation showed that the treatment of islet graft recipients with anti-IL-7R from D-21 significantly reduced T cell proliferation in response to stimulation by donor splenocytes (B), but did not alter T cell responses to third party splenocytes (C). (D) IFN- $\gamma$ ELISPOT showed that mice treated with anti-IL-7R from D-21 had significantly fewer IFN- $\gamma$-secreting $T$ cells in response to stimulation by donor splenocytes. (E) Mice treated with anti-IL-7R from D-21 had lower levels of DSAs. (F) BALB/c nude mice underwent islet grafts from C57BL/ 6 donors and then received $5 \times 10^{6}$ of either T cells from BALB/c mice that had been treated with anti-IL-7R from D-21 and become tolerant to C57BL/6 islet grafts or T cells from naive $\mathrm{BALB} / \mathrm{c}$ mice ( $n=4$ for each groups). T cells from tolerant mice were less effective in inducing islet graft rejection than those from naive mice. ${ }^{*} P<0.05 ;{ }^{* *} P<0.01 ;{ }^{* *} P<0.001$.

the other hand, we found that mice sacrificed 4 days after having received A7R34 at a dose as high as $2 \mathrm{mg} / \mathrm{d}$ had not yet exhibited significant reduction in lymphocyte numbers (data not shown), indicating that A7R34 does not have important lytic activity, also in agreement with studies from other groups $(21,23)$.

IL-7R blockade alone started 3 weeks before graft induces islet allograft tolerance and abrogates both cellular and humoral alloimmune responses. We next investigated the effects of IL-7R blockade in a fully mismatched islet allograft model in which C57BL/6 islets were transplanted into BALB/c mice previously rendered diabetic by streptozotocin (STZ). Anti-IL-7R $\alpha \mathrm{mAb}$ given at $400 \mu \mathrm{g}$ qod from the day of graft (D0) until rejection did not significantly prolong graft median survival time (MST) compared with no treatment ( 29 vs. 21 days; $P=0.16$ ). Being guided by the aforementioned experiment in naive mice, we gave anti-IL-7R $\alpha \mathrm{mAb}$ from 3 weeks before grafts (D-21) to posttransplant day 90 (PTD90) and obtained indefinite graft survival of more than 180 days in 5 of 6 treated mice ( $P=0.0002$ compared with no treatment). A shorter period of treatment from D-21 to PTD30 was also sufficient to induce graft tolerance in all treated mice $(P<0.0001 \mathrm{com}-$ pared with no treatment) (Figure $1 \mathrm{~A})$. Subsequent left nephrec- tomy to remove the islet grafts in tolerant mice led to a prompt increase in blood glucose (data not shown), confirming that the maintenance of normoglycemia was due to graft function.

Untreated and some treated mice that received anti-IL-7R from D-21 to PTD30 were sacrificed a few days after graft rejection and on PTD70, respectively, for immunological analyses. Using mixed lymphocyte reaction (MLR) with $3 \mathrm{H}$-thymidine incorporation, we showed that the treatment of islet graft recipients with antiIL-7R $\alpha \mathrm{mAb}$ specifically reduced the $\mathrm{T}$ cell responses to donor APCs (Figure 1B), but did not alter the $\mathrm{T}$ cell responses to third party APCs (Figure 1C), indicating that the tolerance induced by IL-7R blockade is donor specific. Moreover, using IFN- $\gamma$ ELISPOT, we demonstrated that IL-7R blockade abrogated the formation and activation of donor-specific memory $\mathrm{T}$ cells, as evidenced by a significantly lower number of IFN- $\gamma$-secreting $\mathrm{T}$ cells in response to donor APCs (Figure 1D). Of note, IFN- $\gamma$ ELISPOT was negative when third-party APCs were used as stimulators, whether $\mathrm{T}$ cells from untreated or treated mice were used as responders (data not shown). Tolerant mice also had reduced humoral alloimmune responses as evidenced by significantly lower levels of donorspecific antibodies (DSA) (Figure 1E). 


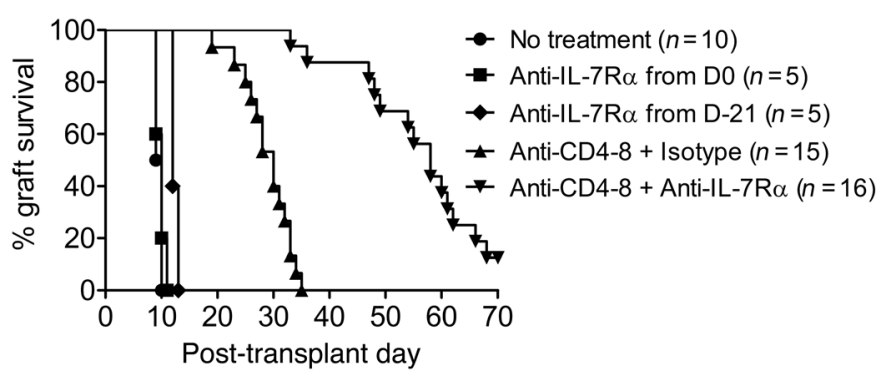

Lymphocyte phenotyping performed on PTD180 showed that lymphocyte reconstitution had occurred in tolerant mice (Supplemental Figure 2). In order to test whether tolerance can be transmissible, T cells purified from the spleen of tolerant mice sacrificed on PTD180 were adoptively transferred to T cell-deficient BALB/c nude mice that had received islet grafts from $\mathrm{C} 57 \mathrm{BL} / 6$ donors. Without $\mathrm{T}$ cell transfer, BALB/c nude mice accepted islet allograft indefinitely. The transfer of $T$ cells from naive wild-type BALB/c to $\mathrm{BALB} / \mathrm{c}$ nude mice that had previously received $\mathrm{C} 57 \mathrm{BL} / 6$ islet graft 2 weeks earlier led to graft rejection in 3 of 4 mice, whereas the same experiment using $\mathrm{T}$ cells from tolerant mice only led to graft rejection in 1 of 4 mice. However, the small sample size ( $n=4$ for each group) precluded statistical analysis (Figure $1 \mathrm{~F}$ ).

IL-7R blockade following T cell depletion strongly prolongs skin allograft survival. We next tested the effects of IL-7R blockade in a much more stringent model of fully allogeneic skin allograft from $\mathrm{C} 57 \mathrm{BL} / 6$ donors to $\mathrm{BALB} / \mathrm{c}$ recipients. Anti-IL-7R $\alpha \mathrm{mAb}$ given alone either from D0 or D-21 until rejection did not result in a meaningful prolongation of graft MST compared with no treatment (10 vs. 9.5 days; $P=0.37$ and 12 vs. 9.5 days; $P=0.0006$, respectively) (Figure 2). Because IL-7R blockade is expected to inhibit $\mathrm{T}$ cell reconstitution after $\mathrm{T}$ cell depletion therapy, we then tested whether the addition of an anti-IL-7R $\alpha \mathrm{mAb}$ to a $\mathrm{T}$ cell depletion protocol could prolong skin graft survival. We treated recipient mice first with a combination of 2 depleting $\mathrm{mAbs}$, antiCD4 and anti-CD8 in order to rapidly deplete T cells, followed by either isotype control or anti-IL-7R $\alpha \mathrm{mAb} 400 \mu \mathrm{g}$ qod from PTD1 until rejection. Mice having received anti-CD4 and anti-CD8 followed by isotype control (referred to as "depletion alone") had graft MST of 30 days (range: $19-35$ days) $(P<0.0001$ compared with untreated mice). Mice having received anti-CD4 and antiCD8 followed by anti-IL-7R $\alpha$ mAb (referred to as "depletion plus anti-IL-7R") had MST of 58 days (range: 36 to >90 days), which were significantly longer than that of the "depletion alone" group $(P<0.0001)$ (Figure 2).

$I L-7 R$ blockade following $T$ cell depletion delays $T$ cell reconstitution and favors immuno regulation. First of all, we compared the total $T$ cell and $\mathrm{T}$ cell subset numbers among 4 groups of skin graft recipients having received no treatment, anti-IL-7R alone from D0, antiIL-7R alone from D-21, and T cell depletion by anti-CD4 and anti$\mathrm{CD} 8$, followed by anti-IL-7R and found that a profound reduction of T cells, including CD4+FOXP3- effector $\mathrm{T}$ cells such as achieved with the last regimen was necessary for the prolongation of skin graft survival (Supplemental Figure 3).

We next focused our analyses on the 2 groups of mice treated by depletion alone and depletion plus anti-IL-7R and compared the lymphocyte subset numbers and frequencies between these 2 groups on PTD35. At this time point, mice that received deple-

\section{Figure 2}

IL-7R blockade following T cell depletion strongly prolongs skin allograft survival. BALB/c mice received skin graft from C57BL/6 donors and were treated as indicated. T cell depletion by a combination of anti-CD4 and anti-CD8 mAbs prolonged graft survival compared with no treatment ( 30 vs. 9.5 days; $P<0.0001$ ). The addition of IL-7R blockade to T cell depletion doubled graft MST compared with T cell depletion alone (58 vs. 30 days; $P<0.0001$ ). tion alone had rejected their grafts, whereas grafts were well preserved in mice under the cover of depletion plus anti-IL-7R. We found that IL-7R blockade following $\mathrm{T}$ cell depletion profoundly inhibited $\mathrm{T}$ cell reconstitution. Mice with depletion plus antiIL-7R had a 10- to 20-fold reduction in the number of total T cells, $\mathrm{CD}^{+}$and $\mathrm{CD}^{+} \mathrm{T}$ cells in the LNs, spleen, and peripheral blood compared with mice with depletion alone (all $P<0.05$ ) (Figure 3, A and B, and Supplemental Figure 4, A and B). B cell numbers were also reduced but to a lesser extent. The effect of IL-7R blockade on the thymus was even more pronounced (Supplemental Figure 4C). The fact that anti-CD4 and anti-CD8 mAbs did not deplete B cells (Supplemental Figure 4D) whereas IL-7R blockade in mice reduced both $\mathrm{T}$ and $\mathrm{B}$ cell numbers explains why $\mathrm{B}$ cell number was reduced in the group with depletion plus anti-IL-7R compared with depletion alone.

Despite a decrease in their absolute numbers, the relative frequencies of $\mathrm{CD}^{+} \mathrm{FOXP}^{+}$Tregs were increased in the depletion plus anti-IL-7R group compared with the depletion alone group $(22.3 \% \pm 7.7 \%$ vs. $10.5 \% \pm 0.9 \%$ and $27.4 \% \pm 3.5 \%$ vs. $14.4 \% \pm 0.8 \%$ of $\mathrm{CD}^{+} \mathrm{T}$ cells in the LNs and spleen, respectively; both $P<0.05)$. As a result, the Treg/T effector ratio defined by $\mathrm{CD}^{+}{ }^{+} \mathrm{CD} 4{ }^{+} \mathrm{FOXP} 3^{+} / \mathrm{CD}^{+}{ }^{+} \mathrm{CD} 4{ }^{+} \mathrm{FOXP} 3^{-}$was increased $(0.30 \pm 0.13$ vs. $0.12 \pm 0.02$ and $0.38 \pm 0.07$ vs. $0.17 \pm 0.01$ in the LNs and spleen, respectively; both $P<0.05)$. Of note, $\mathrm{CD}^{+} \mathrm{FOXP}^{+}$ Tregs comprised $\mathrm{CD}^{+}{ }^{+} \mathrm{CD} 25^{+} \mathrm{FOXP}^{+}$and $\mathrm{CD} 4^{+} \mathrm{CD} 25^{-} \mathrm{FOXP}^{+} \mathrm{T}$ cells; the percentage of both populations was increased by IL-7R blockade (Figure 3A). Similarly, the percentage of memory T cells defined as $\mathrm{CD}^{+} \mathrm{CD} 62 \mathrm{~L}^{\text {lo }} \mathrm{CD} 44^{\text {hi }}$ among total $\mathrm{T}$ cells was increased in the depletion plus anti-IL-7R group; however, because of the severe overall reduction in $\mathrm{T}$ cell number, the absolute number of memory $T$ cells in this group was decreased by 8 -fold in the LNs $\left(0.33 \pm 0.18\right.$ vs. $2.46 \pm 0.62 \times 10^{5}$ cells; $\left.P<0.05\right)$ and by 4 -fold in the spleen $\left(2.5 \pm 0.3\right.$ vs. $9.5 \pm 2.0 \times 10^{5}$ cells; $\left.P<0.05\right)$ compared with the depletion alone group. Interestingly, mice treated with depletion plus IL-7R blockade exhibited a 3- to 6-fold increase in the frequency of $\mathrm{CD}^{+} \mathrm{T}$ cells expressing PD- 1 compared with mice treated with depletion alone $(35.0 \% \pm 3.4 \%$ vs. $6.0 \% \pm 1.0 \%$ and $29.0 \% \pm 3.6 \%$ vs. $10.2 \% \pm 1.2 \%$ of $\mathrm{CD}^{+} \mathrm{T}$ cells in the LNs and in the spleen, respectively; both $P<0.05$ ).

Given the striking increase in the expression of PD-1 and the increased Treg/T effector ratio, we further investigated the roles of these 2 immunoregulatory mechanisms. We performed additional skin grafts using the depletion plus anti-IL-7R treatment protocol. From PTD7, we treated recipients with either an anti-PD-L1 mAb (10F9G2) given at $200 \mu \mathrm{g}$ twice per week for 2 weeks to block the PD-1/PD-L1 pathway (24) or an anti-CD25 mAb (PC61) given at $500 \mu \mathrm{g}$ qod for a total of 4 doses to deplete Tregs (25). PD-1/PD-L1 blockade has been shown to abrogate the protective effects of 

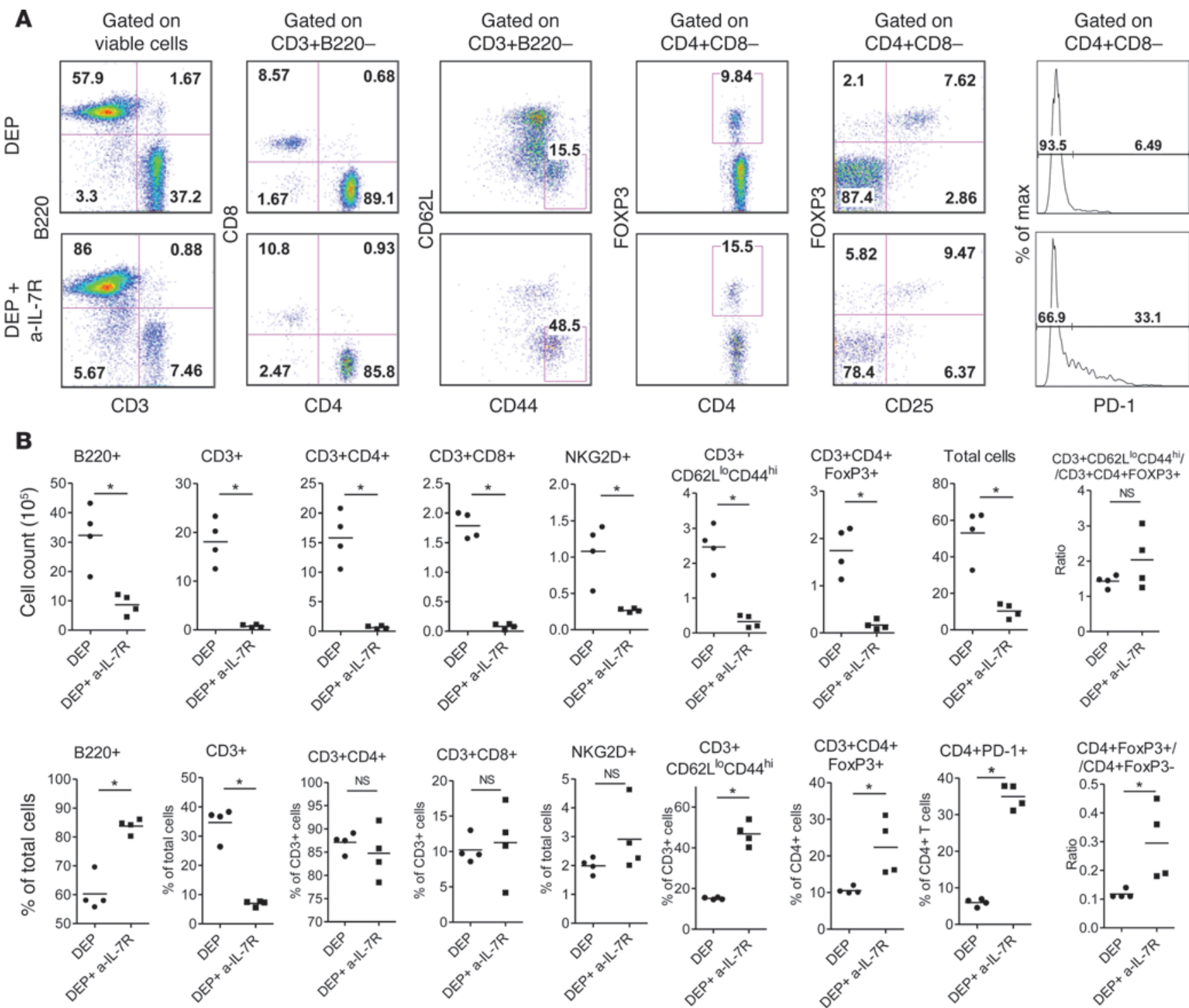

$\mathrm{CD} 3+$
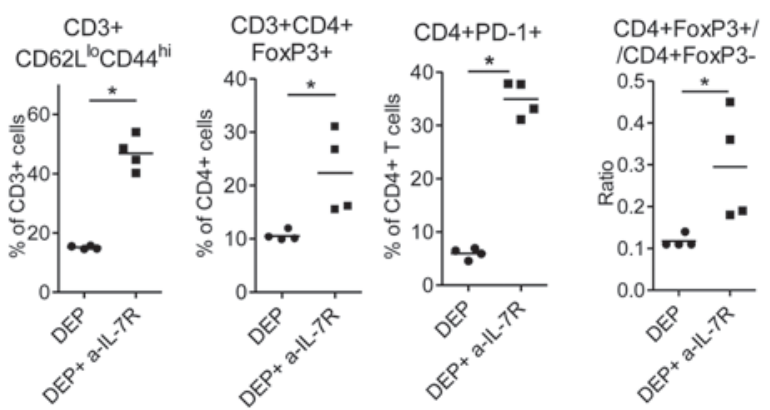

Figure 3

IL-7R blockade following T cell depletion inhibits lymphocyte reconstitution and favors immunoregulation. C57BL/6 skin was transplanted to $\mathrm{BALB} / \mathrm{c}$ recipients, which were treated with $\mathrm{T}$ cell depletion by a combination of anti-CD4 and anti-CD8 mAbs, followed by either isotype lg (DEP) or anti-IL-7R $\alpha \mathrm{mAb}$ (DEP + a-IL-7R) and were then sacrificed at PTD35 for lymphocyte phenotyping. (A) Representative FACS plots of the LNs in which 20,000 events in the viable cell gate were acquired for each sample. Shown are the percentages of lymphocyte subsets. (B) The absolute numbers and the percentages of different lymphocyte subpopulations in the LNs are compared between the 2 groups. The relative frequency of CD4+FoxP3 ${ }^{+}$Tregs was increased in the DEP + a-IL-7R group despite a decrease in their absolute number. See also Supplemental Figure 3 for the spleen, peripheral blood, and thymus. ${ }^{*} P<0.05$.

anti-IL-7R treatment in an autoimmune diabetes model $(21,22)$ and to accelerate rejection in several transplant models (26). Surprisingly, the addition of anti-PD-L1 to our treatment protocol did not alter graft survival (Figure 4), suggesting that this pathway is not crucial for the prolongation of skin graft survival by IL-7R blockade. An alternative explanation is that, under the cover of IL-7R blockade following $\mathrm{T}$ cell depletion, a treatment with multiple mechanisms of action, a contributive role of the PD-1 signaling pathway may become less visible. On the other hand, Treg depletion shortened skin graft MST from 58 days to 48 days (Figure 4), although the difference only had a borderline statistical significance $(P=0.06)$ perhaps due to small sample size $(n=5)$. This trend suggests that the increase in Treg relative frequency may be one of the underlying mechanisms of IL-7R blockade that favors skin graft survival.

IL-7R blockade following $T$ cell depletion abrogates both cellular and bumoral alloimmune responses. IFN- $\gamma$ ELISPOT revealed significantly fewer donor-specific IFN- $\gamma$-secreting $\mathrm{T}$ cells in skin graft recipients treated with depletion plus anti-IL-7R compared with those treated with depletion alone $\left(29 \pm 26\right.$ vs. $203 \pm 76$ spots $/ 10^{5}$ T cells; $P<0.0005$ ) (Figure 5A). Similarly, MLR with $3 \mathrm{H}$-thymidine incorporation showed a very weak donor-specific $\mathrm{T}$ cell response in mice treated with depletion plus anti-IL-7R, whereas there was 
a strong $\mathrm{T}$ cell proliferation in mice treated with depletion only $(245 \pm 55$ vs. $11410 \pm 6456$ counts per minute; $P<0.0001)$ (Figure $5 \mathrm{~B})$. Of note, unlike in the islet graft model, $\mathrm{T}$ cell proliferation in response to third party splenocytes was also inhibited in mice treated with depletion plus anti-IL-7R (data not shown). Cytokine measurement in the MLR supernatant by ELISA also showed a complete abrogation of IL-2, TNF, and IL-17 secretion by $\mathrm{T}$ cells from mice with depletion plus anti-IL-7R compared with mice with depletion only $(8.0 \pm 4.4$ vs. $79.8 \pm 38.1,16.8 \pm 8.3$ vs. $140.1 \pm 25.5$, and $2.5 \pm 2.2$ vs. $62.0 \pm 33.8 \mathrm{pg} / \mathrm{ml}$, respectively; all $P<$ 0.01 ) (Figure 5C). Together, these data show that T cells that have escaped depletion may become anergic to donor APCs and suggest that the effects of IL-7R blockade are not restricted to depletion. The humoral alloimmune response was also abrogated, as evidenced by a significant reduction in DSA levels in mice treated with depletion plus anti-IL-7R compared with mice treated with depletion only (616 \pm 311 vs. $4101 \pm 1877 ; P<0.0001)$ (Figure 5D).

Because IL-7R blockade following $\mathrm{T}$ cell depletion leads to a decrease in memory $\mathrm{T}$ cell numbers and an inhibition of alloimmune responses, we wonder whether this treatment is effective in alloimmunized mice and whether it would also affect the antiviral immune responses acquired through previous infections or vaccinations. To address the first question, we performed skin grafts from $\mathrm{C} 57 \mathrm{BL} / 6$ donors to $\mathrm{BALB} / \mathrm{c}$ recipients without treatment; as expected, all grafts were rejected within 10 days. One month after the first graft, recipients were rechallenged with a second C57BL/ 6 skin graft and divided into 3 groups: depletion plus anti-IL-7R, depletion alone, and no treatment. Although we also observed a statistically significant prolongation of graft survival in the group treated by depletion plus anti-IL-7R compared with depletion alone or no treatment $(\mathrm{MST}=15,11$, and 6 days, respectively; $P<0.05$ ) (Supplemental Figure 5), graft survival was far shorter than that obtained in nonpreimmunized recipients (Figure 2), suggesting that IL-7R blockade following $\mathrm{T}$ cell depletion is less effective when recipients have been primed by a first graft.

To address the second question, we used a model of viral infection in which naive BALB/c mice received $2 \mathrm{i} . \mathrm{m}$. injections of $10^{10}$ infectious particles of an adenovirus vector serotype 5 (AdV5) at 4 weeks apart. Two weeks after the second injection, mice received PBS for 5 weeks, anti-IL-7R $\alpha$ mAb for 5 weeks, or T cell depletion by 2 injections of anti-CD 4 and anti-CD 8 mAbs followed by anti-IL-7R $\alpha \mathrm{mAb}$ for 7 weeks and then were sacrificed for analyses. ELISA showed no difference in anti-adenovirus antibody titers among the 3 groups of mice (Supplemental Figure 6A). IFN- $\gamma$ ELISPOT also revealed no difference in the frequency of antiadenoviral memory $\mathrm{T}$ cells between the control group and the group that received anti-IL-7R alone for 5 weeks (Supplemental Figure $6 \mathrm{~B}$ ), suggesting that a short course of IL-7R blockade by itself does not impair previously acquired antiviral immunity. However, $\mathrm{T}$ cell depletion by anti-CD 4 and anti-CD8 followed by anti-IL-7R for 7 weeks led to a decrease in the frequency of antiadenoviral memory $\mathrm{T}$ cells, as expected in the case of a strong immunosuppressive regimen. Therefore, IL-7R blockade following $\mathrm{T}$ cell depletion is likely to be more suitable for an induction rather than a long-term maintenance therapy in transplantation.

$T$ cell targeting is critical for the efficacy of anti-IL-7R therapy in the prolongation of skin graft survival. Our aforementioned data demonstrated that IL-7R blockade exerts its effects through targeting T cells; however, at least in mice, B cells are also affected by IL-7R blockade. Therefore, we further clarify the role B cells in our treat-

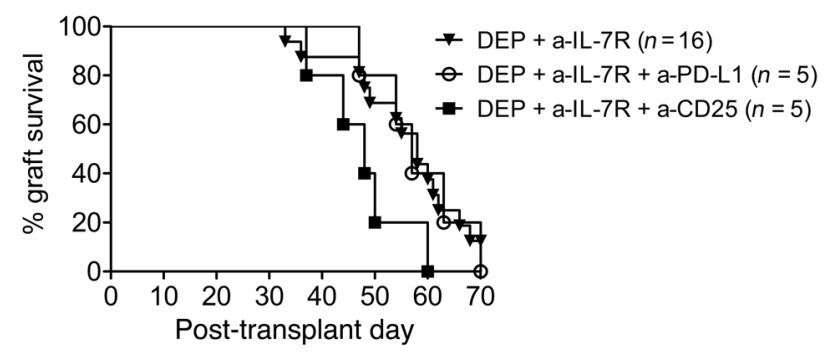

\section{Figure 4}

Treg depletion decreases skin graft survival. C57BL/6 skin was transplanted to $B A L B / c$ recipients, which were treated with $T$ cell depletion by a combination of anti-CD4 and anti-CD8 mAbs, followed by antiIL-7R $\alpha$ mAb (DEP + a-IL-7R). Some recipients were also treated with either an anti-PD-L1 mAb to block the PD-1/PD-L1 signaling pathway or an anti-CD25 mAb to deplete Tregs. As also shown in Figure 2, treatment with DEP + a-IL-7R resulted in graft MST of 58 days; the addition of anti-PD-L1 did not alter graft survival (MST $=57$ days; $P=0.89 \mathrm{com}$ pared with DEP + a-IL-7R), whereas the addition of anti-CD25 shortened graft MST to 48 days $(P=0.06$ compared with DEP $+\mathrm{a}-\mathrm{IL}-7 \mathrm{R})$.

ment protocols. We performed skin grafts from BALB/c donors to $B$ cell-deficient muMT mice and treated recipients with the same treatment protocols used in wild-type mice to investigate whether the absence of B cells affects graft survival. In agreement with a previous report (27), untreated muMT mice rejected BALB/c skin graft as rapidly as wild-type $\mathrm{C} 57 \mathrm{BL} / 6$ mice did (MST $=9.5$ days in both cases). Anti-IL-7R $\alpha$ mAb given alone from D0 failed to prolong graft survival (MST $=9.5$ days). On the other hand, $\mathrm{T}$ cell depletion by anti-CD4 and anti-CD8 mAbs prolonged graft survival to 33 days ( $P=0.002$ compared with no treatment), and the addition of anti-IL-7R $\alpha \mathrm{mAb}$ to T cell depletion further prolonged skin graft MST to 52 days $(P=0.0007$ compared with depletion alone) (Figure 6A). Indeed, under each treatment protocol, graft survival obtained in muMT mice was comparable to that obtained in wild-type mice (Figure 2), indicating that the absence of B cells does not affect the protective effects of IL-7R blockade on graft survival. Interestingly, despite the lack of $\mathrm{B}$ cell antigen presentation, muMT mice were able to develop a strong donor-specific memory $\mathrm{T}$ cell response as shown by IFN- $\gamma$ ELISPOT (Figure 6B). As in wild-type mice (Figure $5 \mathrm{~A}$ ), $\mathrm{T}$ cell responses in muMT mice were also abrogated by the treatment with IL-7R blockade following $\mathrm{T}$ cell depletion (Figure 6B).

Because IL-7R blockade following T cell depletion reduced DSA levels, we wondered whether that effect is also due to the decrease in $\mathrm{B}$ cell number besides the diminution of $\mathrm{T}$ cell help. Therefore, we gave BALB/c mice an anti-mouse CD20 mAb (5D2) at $100 \mu \mathrm{g}$ on D-3 and D-1 to deplete B cells (Figure $6 \mathrm{C}$ ) and then performed skin grafts from $\mathrm{C} 57 \mathrm{BL} / 6$ donors. Although B cell depletion by anti-CD20 did not prolong graft survival (MST = 10 days), it significantly reduced DSA levels compared with those of untreated mice (Figure 6D). Taken together, our data show that the effects of IL-7R blockade on T cells are essential for the prolongation of skin allograft survival, but the decrease in B cell number associated with IL-7R blockade may contribute to the reduction in DSA.

IL-7R blockade following $T$ cell depletion abrogates leukocyte infiltration and decreases proinflammatory gene expression in the skin graft. On PTD21, the skin grafts from mice with depletion alone were characterized by a moderate to dense leukocyte infiltrate, whereas 
A

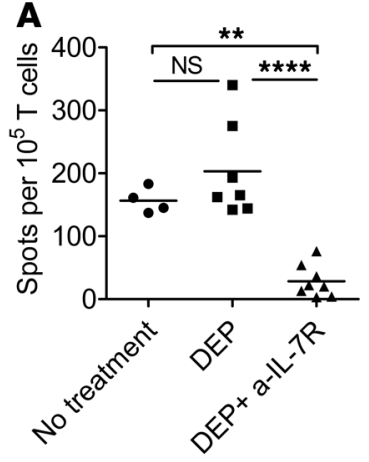

C

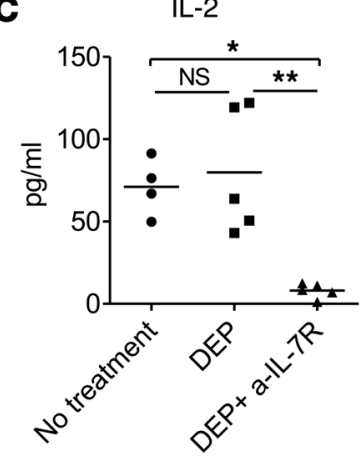

B
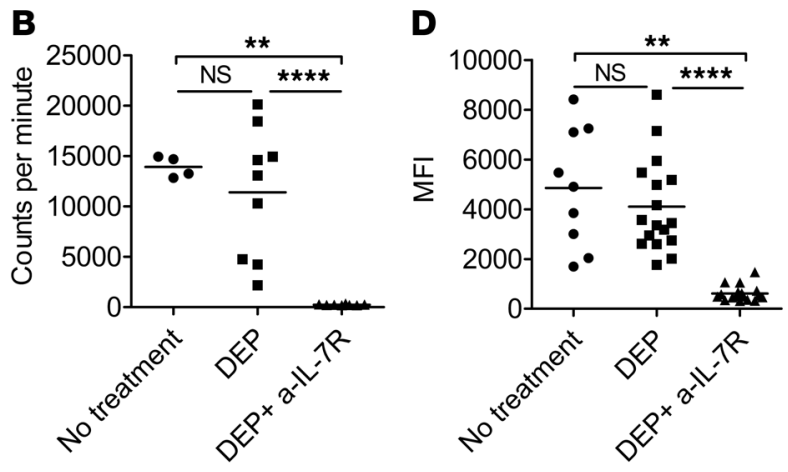

IL-17

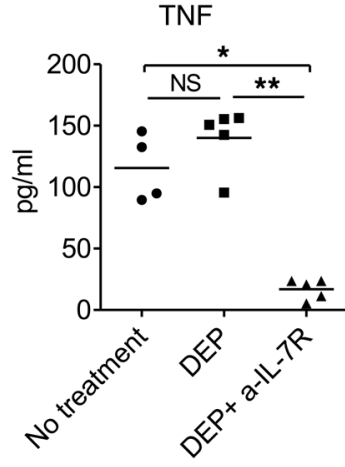

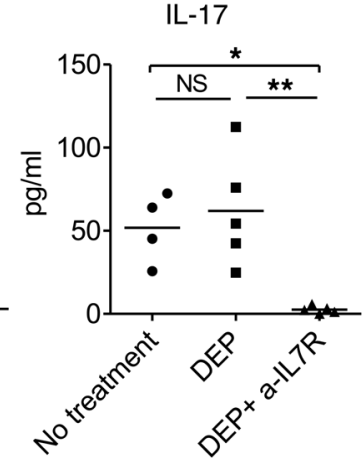

\section{Figure 5}

IL-7R blockade following $T$ cell depletion abrogates both cellular and humoral alloimmune responses. C57BL/6 skin was transplanted to BALB/c recipients, which were untreated or treated with $T$ cell depletion by a combination of antiCD4 and anti-CD8 mAbs followed by either isotype Ig (DEP) or anti-IL-7R $\alpha$ $m A b$ (DEP + a-IL-7R). The donor-specific alloimmune responses of these 3 groups were quantified using IFN- $\gamma$ ELISPOT (A), MLR with ${ }^{3} \mathrm{H}$ thymidine incorporation (B), cytokine measurement in the MLR supernatants by ELISA (C), and DSA measurement in the sera (D). ${ }^{*} P<0.05$; ${ }^{* *} P<0.01 ;{ }^{* * *} P<0.0005$. there was little inflammatory infiltration in the skin grafts from mice with depletion plus anti-IL-7R (Figure 7A). Concordantly, gene expression measurement using TaqMan Low Density Array (TLDA) revealed several-fold decreases in the expression of proinflammatory genes in the skin grafts of mice treated with depletion plus anti-IL-7R compared with those of mice treated with depletion alone. Among these genes were genes coding Th 1 cytokine (IFN- $\gamma$ and TNF), Th2 cytokines (IL-4, IL-5, and IL-13), chemokines (CCL-2, CCL-3, CCL-5, CXCL-10, and CXCL-11), costimulatory molecules (CD40, CD86, and ICOS), granzyme B, and perforin (Figure $7 \mathrm{~B}$ and Table 1).

By PTD70, however, most skin grafts under treatment by depletion plus anti-IL-7R had also been rejected. Lymphocyte phenotyping at the time of graft rejection revealed that all lymphocyte subset numbers in all lymphoid organs were still very low, comparable to those observed earlier on PTD35 (Supplemental Figure 7 ). The skin is well known for its immunogenicity (reviewed in ref. 28) and contains abundant Langerhans cells, whose development is not IL-7 dependent (29). Therefore, skin grafts may be a preferential site for $\mathrm{T}$ cell homing, explaining why they are still rejected despite the persistence of lymphopenia.

We next performed immunohistology of skin grafts of mice treated by depletion plus anti-IL-7R at the time of rejection to see which types of cells participate in the rejection process. For comparison, we also did immunohistological staining of accepted skin grafts under treatment by depletion plus anti-IL-7R on PTD35 as well as rejecting skin grafts of untreated control mice. As shown in Supplemental Figure 8, accepted skin grafts of treated mice on PTD35 had little inflammatory infiltration. When rejection occurred, skin grafts of treated mice were characterized by an influx of leukocytes including macrophages, granulocytes, and $\mathrm{T}$ cells. However, the leukocyte infiltration in the rejecting skin grafts of treated mice was still less intense than that in untreated mice. We also quantified the expression of inflammatory genes in rejecting and accepted skin grafts and found a similar tendency. In mice treated by IL-7R blockade following $\mathrm{T}$ cell depletion, skin grafts undergoing rejection displayed an increase in the expression of inflammatory gene transcripts compared with accepted skin grafts on PTD35 (Supplemental Figure 9A). However, the levels of inflammatory gene expression in rejecting skin grafts of treated mice were still significantly lower than those of untreated control mice (Supplemental Figure 9B).

$I L-7 R$ blockade synergizes with treatment protocols combining $T$ cell depletion with either CTLA-4Ig or low-dose tacrolimus. In order to further prolong skin graft survival, we added either CTLA-4Ig (abatacept) or low-dose tacrolimus to the treatment protocols. CTLA-4Ig alone or low-dose tacrolimus alone only slightly prolonged graft MST (11 days for either treatment compared with 9.5 days for no treatment; $P<0.01)$. CTLA-4Ig combined with T cell depletion by anti-CD4 and anti-CD8 prolonged MST to 28.5 days, and the addition of anti-IL-7R $\alpha \mathrm{mAb}$ to this treatment protocol further increased MST to 52.5 days $(P<0.05)$ (Figure 8A).

The synergistic effect was more pronounced when low-dose tacrolimus was used instead of CTLA4-Ig. Two-thirds of mice treated with a combination of $\mathrm{T}$ cell depletion, low-dose tacrolimus from the day of graft, and anti-IL-7R $\alpha$ mAb from PTD1 to PTD70 had skin graft survival of at least 90 days, whereas mice treated with the same protocol but without IL-7R blockade had MST of only 32.5 days $(P<0.001)$ (Figure 8B). We next investigated whether we could shorten the duration of anti-IL-7R treatment to facilitate immune reconstitution. At the same time, we also started low-dose tacrolimus from PTD12 instead of D0 to reduce immunosuppression in the early phase of lymphodepletion. We found that $80 \%$ of mice treated with IL-7R blockade following $\mathrm{T}$ cell depletion and low-dose tacrolimus from PTD12 had graft survival of at least 90 days whether anti-IL-7R $\alpha$ mAb was stopped on 
PTD70 or PTD35, indicating that a short course of anti-IL-7R $\alpha$ $\mathrm{mAb}$ is sufficient to prolong graft survival in this drug combination. On the contrary, mice treated with $\mathrm{T}$ cell depletion and lowdose tacrolimus from PTD12 but without anti-IL-7R $\alpha \mathrm{mAb}$ had skin graft MST of only 33 days $(P<0.005)$ (Figure $8 B$ ). Importantly, lymphocyte phenotyping on PTD90 showed that the shorter course of anti-IL-7R treatment was associated with a better recovery of thymic function and a higher number of $\mathrm{T}$ and $\mathrm{B}$ cells in the LNs (Figure 8C), thereby limiting the potential overimmunosuppression associated with prolonged lymphopenia.

\section{Discussion}

Inhibition of IL-7 or IL-7R by specific blocking mAbs has been successfully tested in models of autoimmune diseases $(21,22$, 30-32) and graft-versus-host disease following bone marrow transplantation (33). In the context of organ transplantation, there is a single report in which an anti-mouse IL-7 polyclonal $\mathrm{Ab}$ had no effect when given alone, but prolonged heart graft survival when combined with CD40/CD40L costimulatory blockade (34).

Using an islet allograft model, we demonstrated that tolerance could be achieved when anti-IL-7R $\alpha \mathrm{mAb}$ was given alone from 3 weeks before graft (Figure 1A). Because this blocking mAb does not have a rapid lytic effect, it must take a few weeks to obtain a significant reduction in lymphocyte numbers (Supplemental Figure 1). However, once established, tolerance persisted despite lymphocyte reconstitution after the end of anti-IL-7R treatment (Supplemental Figure 2) and tolerant mice developed donorspecific hyporesponsiveness (Figure 1, B-D). Furthermore, T cells from tolerant mice did not induce islet graft rejection in $\mathrm{T}$ celldeficient nude mice as effectively as $\mathrm{T}$ cells from naive mice (Figure $1 \mathrm{~F})$. Taken together, these data indicate that immunoregulation was established after a short course of IL-7R blockade. However, this model might overestimate the efficacy of IL-7R blockade because STZ has recently been demonstrated to induce lymphopenia associated with an increase in Treg frequency and produce immunosuppressive effects (35).

Therefore, we next used a more stringent model of fully mismatched skin allograft and demonstrated that the addition of IL-7R blockade to T cell depletion therapy inhibited T cell reconstitution and doubled graft MST (Figure 2). The mechanisms underlying the prolongation of skin graft survival using this treatment protocol are multifactorial. The most evident effect of IL-7R blockade following $\mathrm{T}$ cell depletion is the extended reduction of lymphocyte numbers affecting the majority of lymphocyte subpopulations, including $\mathrm{T}$ cells, $\mathrm{B}$ cells, $\mathrm{CD} 4^{+} \mathrm{T}$ cells, $\mathrm{CD}^{+} \mathrm{T}$ cells, and especially the $\mathrm{CD} 62 \mathrm{~L}^{\text {lo }} \mathrm{CD} 44^{\text {hi }}$ memory $\mathrm{T}$ cells known to be associated with graft rejection (4, 5). IL-7R blockade delays postdepletional T cell recovery though both a suppression of thymopoiesis (20) and an inhibition of $\mathrm{T}$ cell homeostatic proliferation $(14,16,17)$.

The inhibitory effect of IL-7R blockade following T cell depletion on allospecific memory $\mathrm{T}$ cell formation and activation as demonstrated by IFN- $\gamma$ ELISPOT and MLR (Figure 5, A and B) is also a contributing mechanism. Moreover, $\mathrm{T}$ cells from mice that accepted their skin graft under IL-7R blockade secreted much less Th1 and Th17 cytokines (Figure 5C), a finding in concordance with previous studies using models of autoimmune diseases $(21,22,30)$. Similarly, accepted skin grafts under IL-7R blockade expressed much lower levels of proinflammatory cytokines (Figure 7B and Table 1).

\section{Table 1}

List of genes significantly suppressed in the skin grafts of mice treated with depletion plus anti-IL-7R (A) compared with depletion + isotype $\lg (I)$

\begin{tabular}{|c|c|}
\hline Genes & $\log _{2} \mathrm{FC}(\mathrm{A} / \mathrm{I})$ \\
\hline$/ / 13$ & $-7,4$ \\
\hline /14 & $-6,8$ \\
\hline$/ / 1 b$ & $-5,5$ \\
\hline Ifng & $-4,5$ \\
\hline 116 & $-4,5$ \\
\hline Ptgs2 & $-4,0$ \\
\hline Gzmb & $-3,9$ \\
\hline $1 / 3$ & $-3,9$ \\
\hline $\mathrm{Ccl} 3$ & $-3,7$ \\
\hline Icos & $-3,6$ \\
\hline Cxcl11 & $-3,5$ \\
\hline Stat4 & $-3,2$ \\
\hline II2ra & $-3,1$ \\
\hline Csf2 & $-3,0$ \\
\hline Ccl5 & $-2,9$ \\
\hline Prf1 & $-2,5$ \\
\hline CD40 & $-2,5$ \\
\hline$/ / 10$ & $-2,4$ \\
\hline 115 & $-2,2$ \\
\hline Fasl & $-2,1$ \\
\hline Cxc/10 & $-2,0$ \\
\hline Ccl2 & $-1,8$ \\
\hline Tnf & $-1,7$ \\
\hline $\mathrm{H} 2-\mathrm{Ea}$ & $-1,6$ \\
\hline$H 2-E b 1$ & $-1,5$ \\
\hline Stat1 & $-1,2$ \\
\hline CD86 & $-1,2$ \\
\hline
\end{tabular}

This table reports the relative expression of the genes shown in Figure 7B. FC, fold change.

The increase in Treg/ $\mathrm{T}$ effector ratio associated with IL-7R blockade is likely to contribute to graft acceptance because Treg depletion by anti-CD25 mAb tended to shorten skin graft survival (Figure 4). The role of Tregs in the prolongation of graft survival under lymphopenic conditions is well known; for example, the adoptive transfer of exogenous Tregs to mice treated with costimulatory blockade after having undergone subtotal $\mathrm{T}$ cell depletion restored heart graft tolerance (5). IL-7-deprived Tregs were also shown to maintain their suppressive functions (22).

Since IL-7R blockade in mice affects both $\mathrm{T}$ and $\mathrm{B}$ cells, whereas in human, B cell number is not decreased by IL-7R $\alpha$ mutations, we further investigated the role of B cells in our treatment protocols. Using B cell-deficient muMT mice as skin allograft recipients, we demonstrated that IL-7R blockade following $\mathrm{T}$ cell depletion prolonged graft survival whether B cells were present or absent (Figure 2 and Figure 6A). On the other hand, B cell depletion by anti-CD20 $\mathrm{mAb}$ in wild-type mice, although not sufficient to prolong skin graft survival, led to a significant decrease in DSA levels (Figure 6D).

Taken together, our data show that IL-7R blockade after T cell depletion prolongs skin allograft survival through different mechanisms, including inhibition of $\mathrm{T}$ cell reconstitution, inhibition of the formation and activation of allospecific memory $\mathrm{T}$ cells, and induction of immunoregulation associated with an increase in Treg/T effector ratio. On the other hand, in mice, the reduction in B cell 
A

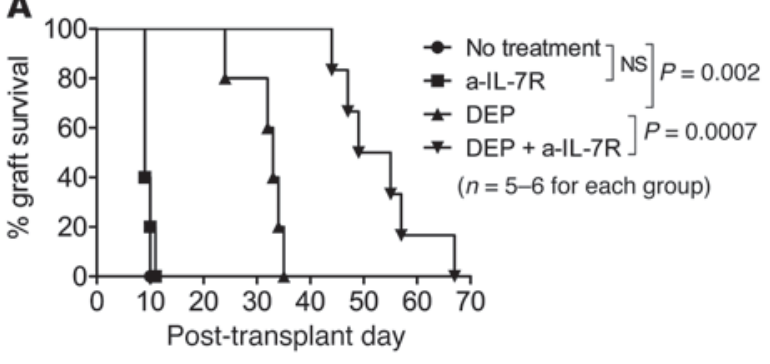

C

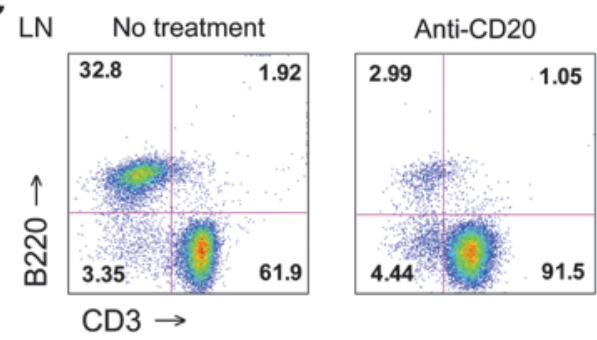

B

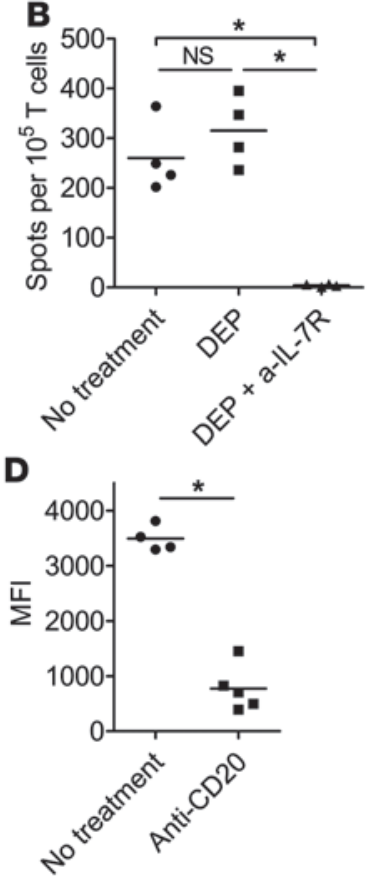

Figure 6

$B$ cell deficiency does not affect skin graft survival, but can reduce DSA. (A and B) $B$ cell-deficient muMT mice received BALB/C skin grafts and were treated as indicated. IL-7R blockade following T cell depletion by anti-CD4 and anti-CD8 effectively prolonged graft survival (A) and abrogated donor-specific $\mathrm{T}$ cell responses, as shown by IFN- $\gamma$ ELISPOT (B). (C and D) BALB/c mice were treated with an anti-CD20 mAb and then received skin grafts from $\mathrm{C} 57 \mathrm{BL} / 6$ donors. Anti-CD20 effectively depleted B cells, as shown by a representative FACS plot on PTD4 (C) and significantly reduced DSA levels on PTD14 (D), but did not prolong graft survival (MST $=10$ days). ${ }^{*} P<0.05$. number caused by IL-7R blockade may contribute to the decrease in DSA and attenuate the B cell-mediated component of rejection.

Finally, combination treatment with other immunosuppressants further enhances graft survival in this stringent skin allograft model. IL-7R blockade following $T$ cell depletion synergized with either CTLA-4Ig or suboptimal doses of tacrolimus (Figure 8, A and $\mathrm{B}$ ). The latter protocol is likely more effective because tacrolimus is more potent than other drugs in inhibiting memory $\mathrm{T}$ cell activation (7), whereas memory $T$ cells have been shown to be less dependent on costimulation for activation $(36,37)$.

However, lymphopoiesis in human and in mice has several differences. Under normal conditions, the maintenance of the $\mathrm{T}$ cell pool in adult humans and in mice is sustained almost exclusively by peripheral $\mathrm{T}$ cell division and by thymic output, respectively (38). But after T cell depletion therapy, the increased thymic output does contribute to immune reconstitution in adult transplant patients (1). We and others found that $\mathrm{T}$ cell numbers returned to normal about 3 months after a brief course of $\mathrm{T}$ cell depletion by anti-CD4 and anti-CD8 mAbs in mice (39), whereas it may take up to 3 years for lymphocyte numbers in the blood of kidney transplant patients treated by alemtuzumab or thymoglobulin induction to return to baseline levels $(40,41)$.

Nevertheless, mouse skin allograft is a predictive preclinical model frequently used in the early phase of development of new immunosuppressive drugs in transplantation (42-44). The skin graft survival obtained in our study is remarkable because, without bone marrow transplantation, not many treatment protocols could result in similar graft outcomes, especially when fully allogeneic BALB/c and C57BL/ 6 mice are used for donors and recipients $(43,44)$. Therefore, our results suggest that IL-7R blockade may present as a promising therapeutic candidate in organ transplantation. Thoroughly designed treatment protocols combining an anti-IL-7R $\alpha$ mAb with other immunosuppressants should harness the beneficial effects of IL-7R blockade to promote allograft acceptance.

\section{Methods}

Mice and allograft models. Eight-week-old male C57BL/6 (H-2b), BALB/c $(\mathrm{H}-2 \mathrm{~d})$, and SJL $(\mathrm{H}-2 \mathrm{~s})$ mice were purchased from Centre d'Elevage Janvier. Six-week-old male BALB/c nude (H-2d) and B cell-deficient muMT mice (B6.129S2-Ighm ${ }^{\mathrm{tm} 1 \mathrm{Cgn} / J)}$ on a C57BL/6 genetic background were purchased from Charles River France. To prepare for islet transplantation, BALB/c or $\mathrm{BALB} / \mathrm{c}$ nude recipients received 1 i.p. injection of $250 \mathrm{mg} / \mathrm{kg}$ of STZ 5 to 10 days before graft to induce diabetes, which is defined as a nonfasting blood glucose greater than $17 \mathrm{mmol} / \mathrm{l}(300 \mathrm{mg} / \mathrm{dl})$ on at least 2 occasions. Pancreases were harvested from C57BL/ 6 donors, digested by collagenase, and islets purified by Ficoll gradient centrifugation. Each diabetic BALB/c mouse received about 500 islets under the left renal capsule. Graft functioning and graft rejection were diagnosed when blood glucose decreased to less than $10 \mathrm{mmol} / \mathrm{l}(180 \mathrm{mg} / \mathrm{dl})$ and increased again to greater than 17 $\mathrm{mmol} / \mathrm{l}$, respectively. For the skin allograft model, tail skin from donors was grafted to the dorsal trunk of recipients and protected by bandage for 6 days. The skin graft was then inspected every day and rejection was defined as graft necrosis of more than $80 \%$ of the surface.

$m A b s$ and treatment protocols. Some mAbs were produced in our lab using the following hybridomas: rat anti-mouse IL-7R $\alpha$ (A7R34), CD4 (GK1.5), CD8 (2.43), and CD25 (PC61). A7R34 was a gift from Shin-Ichi Nishikawa (Laboratory for Stem Cell Biology, RIKEN Center for Developmental Biology, Kobe, Japan), and other hybridomas were purchased from LGC Standards. Rat anti-mouse PD-L1 (10F9G2) was purchased from Bio X Cell, and rat anti-mouse CD20 (5D2) was provided by Genentech. A rat antidinitrophenol (DNP) mAb (LO-DNP-61) was purchased from the Laboratory of Experimental Surgery, Universite Catholique de Louvain (Brussels, Belgium) and used as rat IgG2a isotype control for the anti-IL-7R $\alpha$ mAb. Human CTLA-4Ig (Abatacept; Bristol Myers Squibb) and tacrolimus (Astellas) were purchased from the pharmacy of CHU de Nantes. All treatments were given i.p. Anti-CD4 and anti-CD8 were given in combination on days -3 and -1 before skin graft at $200 \mu \mathrm{g}$ per injection. CLTA-4Ig was given at $500 \mu \mathrm{g}$ once per week from the day of skin graft (D0) to the day of rejection or to PTD70 if there was no rejection. Low-dose tacrolimus was given at $0.5 \mathrm{mg} / \mathrm{kg} / \mathrm{d}$ from the day of skin graft or $0.7 \mathrm{mg} / \mathrm{kg} / \mathrm{d}$ from 
A

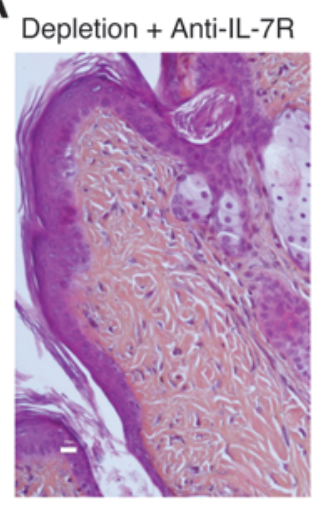

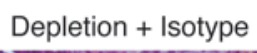

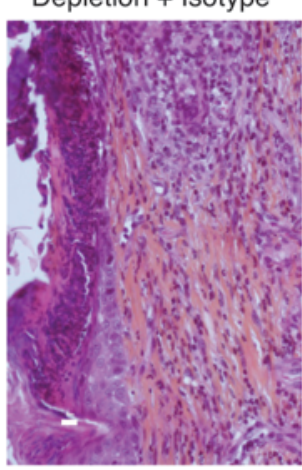

B

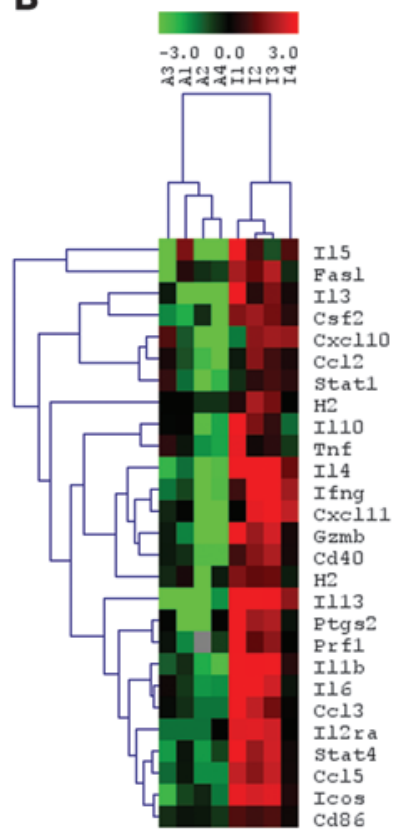

\section{Figure 7}

IL-7R blockade following T cell depletion abrogates leukocyte infiltration and decreases proinflammatory gene expression in the skin graft. C57BL/ 6 skin was grafted to BALB/c recipients, which were treated with $\mathrm{T}$ cell depletion by a combination of anti-CD4 and anti-CD8 mAbs, followed by either isotype $\mathrm{Ig}$ (I1 to I4) or anti-IL-7R $\alpha$ mAb (A1 to A4). (A) Representative photomicrographs of skin graft histology on PTD21 (H\&E). Original magnification, $\times 200$. (B) Unsupervised clustering of differentially expressed genes in skin grafts on PTD21 using mouse immune panel TLDA. The heat map represents normalized and color-coded relative expression values $\left(2^{-\Delta \Delta C q}\right)$. Red values indicate overexpression, and green values indicate underexpression.
PTD12; in either case, it was continued to the day of rejection or to the end of the experiment if there was no rejection. Anti-IL-7R $\alpha \mathrm{mAb}$ was given at $400 \mu \mathrm{g}$ qod; the time and duration of treatment is specified for each experiment in Results. Of note, A7R34 has been effectively used for a relatively long period of time (31), suggesting that the anti-drug Abs that might develop in recipients do not abrogate its effects.

Lymphocyte phenotyping by flow cytometry. Mice were euthanized under general anesthesia. Blood was drawn from cardiac puncture; spleen, thymus, and mesenteric LNs were harvested. Whole-blood leukocyte phenotyping was performed using BD TruCOUNT Tubes (BD Biosciences) according to the manufacturer's instructions. Cells from LNs, spleen, and thymus were isolated using BD Falcon Cell Strainers (BD Biosciences). The following anti-mouse antibodies were used for flow cytometry: anti-CD3, anti-CD4, anti-CD8, anti-CD19, anti-CD44, anti-CD45-2, anti-CD45R (B220), antiCD62L, anti-CD127, anti-Gr-1 (Ly-6G and Ly-6C), anti-NKG2D, antiPD-1 and anti-FOXP3; all were purchased from BD Biosciences except antiFOXP3, which was purchased from eBioscience, and anti-CD127 (A7R34), which was prepared in our lab. Flow cytometry was performed using a BD LSRII flow cytometer.

Measurement of DSA. Blood of recipient mice was obtained either by retroorbital sinus sampling or by cardiac puncture in the case of sacrifice. Plasma was obtained by centrifugation and stored at $-20^{\circ} \mathrm{C}$ for later use. Plasma of recipients was diluted at $1 / 20$ and incubated for 30 minutes with cells freshly isolated from the spleen of a donor mouse. Cells were washed twice, incubated for 15 minutes with an FITC-conjugated goat anti-mouse IgG (Fcy-specific) (Jackson ImmunoResearch) and hamster anti-mouse CD3, washed twice, and analyzed by flow cytometry. DSA levels were reported as MFI.

IFN- $\gamma$ ELISPOT, MLR, and cytokine measurement by ELISA. Skin graft recipients were sacrificed on PTD35, whereas islet graft recipients were sacrificed as indicated in Results. Responder cells were $\mathrm{T}$ cells purified from splenocytes of graft recipients using the Pan-T Cell Isolation Kit II Mouse and autoMACS Pro Separator (both from Miltenyi Biotec) following the manufacturer's instructions. Stimulator cells were irradiated donor splenocytes. Third party cells were irradiated splenocytes from SJL mice (H-2s). Responders were cocultured with either stimulators or third party; each type of cell was seeded at $10^{5}$ cells per well (1:1 ratio) and in triplicate. IFN- $\gamma$ ELISPOT was performed using a mouse IFN- $\gamma$ ELISPOT kit (BD Biosciences). Plates were incubated for 16 hours, washed, and developed according to the manufacturer's instructions and read using an AID Elispot Reader System (AID GmbH). ELISPOT was considered negative when there were fewer than 8 spots per well. For MLR, plates were incubated for 72 hours, pulsed with $3 \mathrm{H}$-thymidine at $1 \mu \mathrm{Ci}$ per well for an additional 16 hours, harvested using a Tomtec Cell Harvester (Tomtec Inc.), and read using a TopCount NXT Microplate Scintillation and Luminescence Counter (PerkinElmer). The MLR supernatants after 72 hours of culture were also stored at $-20^{\circ} \mathrm{C}$ for later cytokine measurement using mouse BD OptEIA ELISA kit (BD Biosciences) for IL-2 and TNF and mouse IL-17 Quantikine ELISA kit (R\&D Systems) for IL-17 according to the manufacturer's instructions.

Skin graft histology and gene expression assay. Skin grafts were harvested when recipients were sacrificed at different time points as indicated. One part of the skin graft was fixed in $4 \%$ formalin for histological studies and the other part cryopreserved for immunohistology and RNA extraction by the TRIzol method (Invitrogen). RNA quality and quantity were determined using an Agilent 2100 BioAnalyzer (Agilent Technologies). RNA was reverse transcribed into CDNA using a poly dT oligonucleotide and Omniscript Reverse Transcriptase kit (QIAGEN). Gene expression assay was performed using TLDA Mouse Immune Panel (Applied Biosystems) according to the manufacturer's instruction. The mean expression of Hprt1 and B2m was used for normalization, and differentially expressed genes were selected using the significance analysis of microarray (SAM) method (45) with false discovery rate below $1 \%$. Unsupervised hierarchical clustering was performed with MultiExperiment Viewer software using uncentered Pearson's correlation with median-centered genes (46).

Evaluation of antiadenoviral immunity. E1/E3-deleted human AdV5 without transgene was obtained from Laboratoire de Therapie Genique (Nantes, France). BALB/c mice were infected with AdV5 and then received treatment as indicated. $\mathrm{T}$ cells and non- $\mathrm{T}$ cells were separated from splenocytes of AdV5-infected mice using Pan-T cell isolation kit 

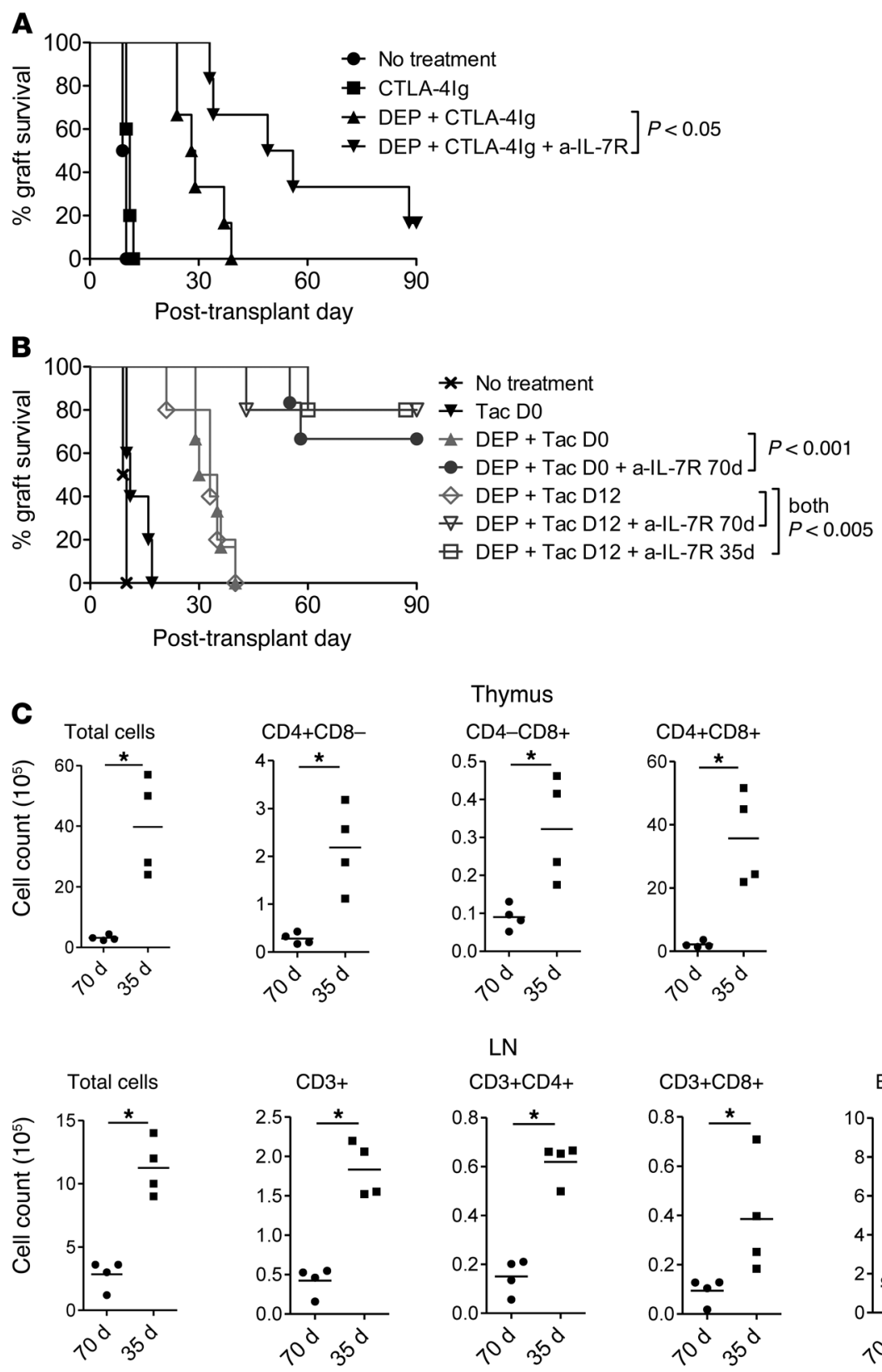

\section{Thymus}

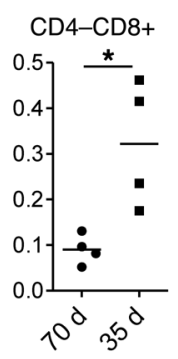

$\mathrm{LN}$

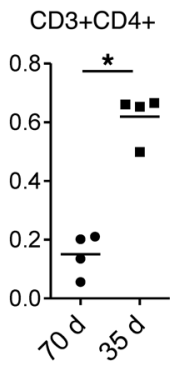

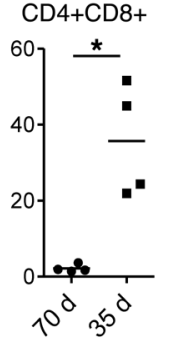

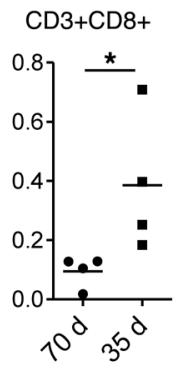

\section{Figure 8}

IL-7R blockade synergizes with treatment protocols combining $T$ cell depletion with either CTLA-4Ig or suboptimal doses of tacrolimus. BALB/c mice received C57BL/6 skin graft and were treated as indicated ( $n=5-6$ for each group). (A) CTLA-4Ig alone only slightly prolonged graft MST compared with no treatment (11 vs. 9.5 days; $P<0.01$ ). CTLA-4Ig combined with $\mathrm{T}$ cell depletion prolonged MST to 28.5 days, and the addition of IL-7R blockade to this treatment protocol further increased MST to 52.5 days $(P<0.05)$. (B) Lowdose tacrolimus (Tac) given from D0 only slightly prolonged graft MST compared with no treatment (11 vs. 9.5 days; $P<0.01$ ). $\mathrm{T}$ cell depletion combined with low-dose tacrolimus given from either D0 or PTD12 prolonged MST to 32.5 or 33 days, respectively, and the addition of anti-IL-7R $\alpha \mathrm{mAb}$ for a duration of either 70 days or 35 days to these 2 treatment protocols further prolonged MST to beyond 90 days in the majority of mice (see figure for direct comparisons between treatment protocols with and without anti-IL-7R $\alpha$ mAb). (C) Lymphocyte phenotyping on PTD90 showed that the shortening of the duration of antiIL-7R treatment from 70 days to 35 days in the DEP + Tac D12 + a-IL-7R protocol was associated with a better lymphocyte recovery in the thymus and in the LNs. ${ }^{*} P<0.05$.
II and autoMACS Pro Separator (Miltenyi Biotec). IFN- $\gamma$ ELISPOT was performed in which each well contained $10^{5} \mathrm{~T}$ cells, $10^{5}$ non-T cells, and $0.3 \mathrm{nmol} /$ peptide/ $\mathrm{ml}$ of a pool of overlapping 15 -mer peptides covering the complete sequence of the hexon protein of adenovirus 5 (Peptivator - AdV5; Miltenyi Biotec). To quantify antiadenoviral antibodies, ELISA plates were coated overnight with $10^{9}$ virus particles per well, washed, and incubated consecutively with serial dilutions of mouse sera (1/500 to $1 / 5000$ ), peroxidase-conjugated donkey anti-mouse IgG (Jackson ImmunoResearch), TMB substrate, and $\mathrm{H} 2 \mathrm{SO} 4$ to stop the reaction, and then read using an ELISA plate reader.

Statistics. Statistics were done using the GraphPad Prism 5.0 software (GraphPad Software). Data were presented as mean \pm SD unless otherwise stated. Graft survivals were reported as MST and analyzed by the KaplanMeier method using the log-rank test. Other values were compared using the Mann Whitney test. $P<0.05$ was considered significant.
Study approval. All animal studies were approved by the institutional review board of INSERM Unit 1064.

\section{Acknowledgments}

The authors thank Shin-Ichi Nishikawa for permission to use A7R34, Ana Cumano for having sent the A7R34 hybridoma, Genentech for providing anti-mouse CD20 (5D2), Effimune for partially funding the project through a research grant, Severine Remy for providing the adenoviral vector, and Claire Usal and Emmanuel Merieau for their technical assistance in animal experimentation.

Received for publication June 14, 2013, and accepted in revised form December 20, 2013. 
Address correspondence to: Jean-Paul Soulillou, INSERM UMR 1064, CHU Hotel Dieu, 30 Bd Jean Monnet, 44093, Nantes Cedex
1, France. Phone: 33.2.40.08.74.10; Fax: 33.2.40.08.74.11; E-mail: soulillou@yahoo.fr.
1. Gurkan S, et al. Immune reconstitution following rabbit antithymocyte globulin. Am J Transplant. 2010;10(9):2132-2141.

2. Sener A, Tang AL, Farber DL. Memory T-cell predominance following T-cell depletional therapy derives from homeostatic expansion of naive $T$ cells. Am J Transplant. 2009;9(11):2615-2623.

3. Engram JC, et al. Lineage-specific T-cell reconstitution following in vivo CD4+ and CD8+ lymphocyte depletion in nonhuman primates. Blood. 2010; 116(5):748-758.

4. Wu Z, et al. Homeostatic proliferation is a barrier to transplantation tolerance. Nat Med. 2004; 10(1):87-92.

5. Neujahr DC, et al. Accelerated memory cell homeostasis during $\mathrm{T}$ cell depletion and approaches to overcome it. J Immunol. 2006;176(8):4632-4639.

6. Kirk AD, et al. Results from a human renal allograft tolerance trial evaluating the humanized CD52specific monoclonal antibody alemtuzumab (CAMPATH-1H). Transplantation. 2003;76(1):120-129.

7. Pearl JP, et al. Immunocompetent T-cells with a memory-like phenotype are the dominant cell type following antibody-mediated T-cell depletion. Am J Transplant. 2005;5(3):465-474.

8. Williams KM, Hakim FT, Gress RE. T cell immune reconstitution following lymphodepletion. Semin Immunol. 2007;19(5):318-330.

9. Tchao NK, Turka LA. Lymphodepletion and homeostatic proliferation: implications for transplantation. Am J Transplant. 2012;12(5):1079-1090.

10. Rochman Y, Spolski R, Leonard WJ. New insights into the regulation of $\mathrm{T}$ cells by gamma(c) family cytokines. Nat Rev Immunol. 2009;9(7):480-490.

11. von Freeden-Jeffry U, Vieira P, Lucian LA, McNeil T, Burdach SE, Murray R. Lymphopenia in interleukin (IL)-7 gene-deleted mice identifies IL-7 as a nonredundant cytokine. J Exp Med. 1995; 181(4):1519-1526.

12. Peschon JJ, et al. Early lymphocyte expansion is severely impaired in interleukin 7 receptor-deficient mice. J Exp Med. 1994;180(5):1955-1960.

13. Giliani $S$, et al. Interleukin-7 receptor alpha (IL-7R $\alpha$ ) deficiency: cellular and molecular bases. Analysis of clinical, immunological, and molecular features in 16 novel patients. Immunol Rev. 2005; 203:110-126

14. Schluns KS, Kieper WC, Jameson SC, Lefrancois L. Interleukin-7 mediates the homeostasis of naive and memory CD8 T cells in vivo. Nat Immunol. 2000;1(5):426-432.

15. Tan JT, et al. IL-7 is critical for homeostatic proliferation and survival of naive T cells. Proc Natl Acad Sci U S A. 2001;98(15):8732-8737.

16. Kondrack RM, Harbertson J, Tan JT, McBreen ME, Surh CD, Bradley LM. Interleukin 7 regulates the survival and generation of memory CD4 cells. J Exp Med. 2003;198(12):1797-1806.
17. Seddon B, Tomlinson P, Zamoyska R. Interleukin 7 and $\mathrm{T}$ cell receptor signals regulate homeostasis of CD4 memory cells. Nat Immunol. 2003; 4(7):680-686.

18. Sprent J, Surh CD. Normal T cell homeostasis: the conversion of naive cells into memory-phenotype cells. Nat Immunol. 2011;12(6):478-484.

19. Racape M, Vanhove B, Soulillou JP, Brouard S. Interleukin 7 receptor alpha as a potential therapeutic target in transplantation. Arch Immunol Ther Exp (Warsz). 2009;57(4):253-261.

20. Sudo T, Nishikawa S, Ohno N, Akiyama N, Tamakoshi M, Yoshida H. Expression and function of the interleukin 7 receptor in murine lymphocytes. Proc Natl Acad Sci U S A. 1993;90(19):9125-9129.

21. Penaranda C, et al. IL-7 receptor blockade reverses autoimmune diabetes by promoting inhibition of effector/memory T cells. Proc Natl Acad Sci U S A. 2012;109(31):12668-12673.

22. Lee LF, et al. Anti-IL-7 receptor- $\alpha$ reverses established type 1 diabetes in nonobese diabetic mice by modulating effector T-cell function. Proc Natl Acad Sci U S A. 2012;109(31):12674-12679.

23. Hoyer KK, Wolslegel K, Dooms H, Abbas AK. Targeting $\mathrm{T}$ cell-specific costimulators and growth factors in a model of autoimmune hemolytic anemia. J Immunol. 2007;179(5):2844-2850.

24. Koehn BH, et al. PD-1-dependent mechanisms maintain peripheral tolerance of donor-reactive CD8+ T cells to transplanted tissue. J Immunol. 2008; 181(8):5313-5322.

25. Shi Q, Lees JR, Scott DW, Farber DL, Bartlett ST. Endogenous expansion of regulatory $\mathrm{T}$ cells leads to long-term islet graft survival in diabetic NOD mice. Am J Transplant. 2012;12(5):1124-1132.

26. Riella LV, Paterson AM, Sharpe AH, Chandraker A. Role of the PD-1 pathway in the immune response. Am J Transplant. 2012;12(10):2575-2587.

27. Ji H, Shen XD, Gao F, Busuttil RW, Zhai Y, KupiecWeglinski JW. Alloreactive CD8 T-cell primed/ memory responses and accelerated graft rejection in B-cell-deficient sensitized mice. Transplantation. 2011;91(10):1075-1081.

28. Al-Adra DP, Anderson CC. Mixed chimerism and split tolerance: mechanisms and clinical correlations. Chimerism. 2011;2(4):89-101.

29. Takeuchi S, Katz SI. Use of interleukin 7 receptor- $\alpha$ knockout donor cells demonstrates the lymphoid independence of dendritic cells. Blood. 2006; 107(1):184-186.

30. Liu X, et al. Crucial role of interleukin-7 in T helper type 17 survival and expansion in autoimmune disease. Nat Med. 2010;16(2):191-197.

31. Gonzalez-Quintial R, et al. Systemic autoimmunity and lymphoproliferation are associated with excess IL-7 and inhibited by IL-7Ralpha blockade. PLoS One. 2011;6(11):e27528.

32. Yamazaki M, et al. Mucosal T cells expressing high levels of IL-7 receptor are potential targets for treatment of chronic colitis. J Immunol. 2003;171(3):1556-1563.

33. Chung B, Dudl EP, Min D, Barsky L, Smiley N, Weinberg KI. Prevention of graft-versus-host disease by anti IL-7Ralpha antibody. Blood. 2007; 110(8):2803-2810.

34. Wang Y, Dai H, Liu Z, Cheng X, Tellides G, Dai Z. Neutralizing IL-7 promotes long-term allograft survival induced by CD40/CD40L costimulatory blockade. Am J Transplant. 2006;6(12):2851-2860.

35. Muller YD, et al. Immunosuppressive effects of streptozotocin-induced diabetes result in absolute lymphopenia and a relative increase of T regulatory cells. Diabetes. 2011;60(9):2331-2340.

36. London CA, Lodge MP, Abbas AK. Functional responses and costimulator dependence of memory CD4+ T cells. J Immunol. 2000;164(1):265-272.

37. Croft M, Bradley LM, Swain SL. Naive versus memory CD4 T cell response to antigen. Memory cells are less dependent on accessory cell costimulation and can respond to many antigen-presenting cell types including resting B cells. J Immunol. 1994;152(6):2675-2685.

38. den Braber I, et al. Maintenance of peripheral naive $\mathrm{T}$ cells is sustained by thymus output in mice but not humans. Immunity. 2012;36(2):288-297.

39. Rice JC, Bucy RP. Differences in the degree of depletion, rate of recovery, and the preferential elimination of naive CD4+ T cells by anti-CD4 monoclonal antibody (GK1.5) in young and aged mice. J Immunol. 1995;154(12):6644-6654.

40. Hanaway MJ, et al. Alemtuzumab induction in renal transplantation. $N$ Engl J Med. 2011; 364(20):1909-1919.

41. Louis S, et al. Long-term cell monitoring of kidney recipients after an antilymphocyte globulin induction with and without steroids. Transplantation. 2007;83(6):712-721.

42. Larsen CP, et al. Long-term acceptance of skin and cardiac allografts after blocking CD40 and CD28 pathways. Nature. 1996;381(6581):434-438.

43. Gilson CR, et al. Anti-CD40 monoclonal antibody synergizes with CTLA4-Ig in promoting long-term graft survival in murine models of transplantation. Jimmunol. 2009;183(3):1625-1635.

44. Reisman NM, Floyd TL, Wagener ME, Kirk AD, Larsen CP, Ford ML. LFA-1 blockade induces effector and regulatory T-cell enrichment in lymph nodes and synergizes with CTLA-4Ig to inhibit effector function. Blood. 2011;118(22):5851-5861.

45. Tusher VG, Tibshirani R, Chu G. Significance analysis of microarrays applied to the ionizing radiation response. Proc Natl Acad Sci U S A. 2001;98(9):5116-5121.

46. Saeed AI, et al. TM4: a free, open-source system for microarray data management and analysis. Biotechniques. 2003;34(2):374-378. 